\title{
Aspects of International Fragmentation
}

\author{
by \\ Wilhelm Kohler (\#) \\ Department of Economics, Johannes Kepler University Linz
}

May 2003

Revised version of Working Paper 0208, JKU Linz, Department of Economics

Fortcoming in Review of International Economics

\begin{abstract}
The paper uses a specific-factors framework to address efficiency and distributional implications of international fragmentation which is driven by a foreign location advantage due to a low wage rate. Focusing on the cost-savings linkage between fragmentation and labor demand in the remaining domestic activities, I establish a fragmentation surplus which is familiar to the immigration surplus. However, if the capital which is specific to the fragment produced abroad is an indivisible asset, then fragmentation may cause a domestic welfare loss, because outsourcing takes place in discrete steps where it affords firms "quasi-market-power" on the domestic labor market. The regime shift from purely domestic production to fragmentation is modeled as a two-stage game. In the first stage firms locate their indivisible assets at home or abroad, and in the second they choose optimal employment. The share of fragmented firms is endogenously determined. The paper explores the conditions determining whether the process of fragmentation caused by less costly outsourcing is beneficial for the domestic economy.
\end{abstract}

(\#): Address: Johannes Kepler University of Linz, Department of Economics, Altenbergerstrasse 69, A-4040 LINZ-AUHOF, Austria. Phone: 0043-732-2468-8239, FAX: - 8238, E-mail: wilhelm.kohler@jk.uni-linz.ac.at, http://www.economics.uni-linz.ac.at/kohler/

This paper was presented at the conference "Adjusting to Globalization", 28th to 29th June 2002, organized by the Leverhulme Centre for Research on Globalisation and Economic Policy (GEP), University of Nottingham. The work has been conducted under a research grant by the Austrian Science Fund under grant no. P14702, entitled "Public Finance, Unemployment and Growth", which is gratefully acknowledged. I am grateful to the Leverhulme Centre for its hospitality at the conference, and to Rod Falvey and Gabriel Felbermayr, as well as two anonymous referees, for helpful comments. 


\section{Introduction}

The traditional view of internationalization rests on a clear distinction between produced commodities and primary factors. According to this view, the principle of international arbitrage operates on goods prices via international exchange of goods, based on a given and well defined underlying value-added process. In addition, it operates on factor prices - directly via international factor movements, and indirectly via the factor price effects of trade. However, recent developments appear to challenge this view. Improvements in communications technology as well as reductions of formal and technical barriers to trade gave rise to a new vehicle of internationalization where international arbitrage cuts valueadded processes into ever smaller slices produced in different locations. ${ }^{1}$ This blurs the distinction between commodity markets and trade on the one hand, and factor movements on the other. What we observe, then, is an international fragmentation of value-added processes which have hitherto been carried out in an integrated way within certain countries. A term often used synonymously is international outsourcing, indicating that single components of a value-added process are shifted to foreign sources where they can be carried out at lower cost. As will become evident below, the phenomenon should not simply be seen as trade in established markets for intermediate goods. The defining feature is that firms are engaged in "fine-tuning" the locational pattern of increasingly fragmented production processes to the international pattern of (unequal) factor prices. In contrast to traditional trade theory, a certain value-added process then no longer takes place under a uniform set of factor prices, but draws on different factor markets for different fragments. The theoretical challenge is to analyse the driving forces and effects of this process of increasing international fragmention. It is quite obvious that this goes beyond extending trade theory to include trade on established markets of existing intermediate goods, which is hardly new, and indeed a largely accomplished task. Essentially, international fragmentation extends the realm of international arbitrage into new ground by "atomizing" production processes. This may give rise to new markets, or the emergence of multinational firms. In either case, the phenomenon we are looking at will often appear more like a "regime shift" than a continuous process, which requires new tools of analysis; see Markusen (2002).

\footnotetext{
${ }^{1}$ See Jones \& Kierzkowski (1990) and Harris (1995).
} 
There is a sizable body of literature demonstrating the empirical significance and theoretical implications of international fragmentation in the recent episode of economic globalization. ${ }^{2}$ In an early paper, Jones \& Kierzkowski (1990) have pointed out that international fragmentation should be beneficial in that it enhances the gains from trade. Krugman (1995) strikes a somewhat less optimistic tone, arguing that it may contribute to the decline of wages for low-skilled labor in industrialized countries. This claim has been further substantiated, both theoretically and empirically, by Feenstra \& Hanson $(1996,1997,1999)$. However, there is no clear-cut theoretical result supporting the view that international fragmentation will generally harm low-skilled labor in industrial countries, in absolute terms or relative to high-skilled labor. Thus, Arndt $(1997,1999)$ argues that labor may benefit, relative to capital, from outsourcing in the US-Mexican context, while papers by Venables (1999), Deardorff (2001a,2001b), and Jones \& Kierzkowski (2001a,2001b) point to a multiplicity of possible factor price effects from fragmentation. In Kohler (2003), I have made an effort to derive general results identifying the common forces at work in all of these cases.

For the policy maker, international fragmentation sometimes arises in a pretty fearsome way in that certain regions all of a sudden face the spectre of losing whole components of value-added chains in certain industries which they may perceive as cornerstones of their economies. There will often be a temptation to "do something about it", particularly with respect to local labor markets. In search of an adequate policy response, it is important to distinguish between efficiency (or welfare) aspects and distributional aspects of international fragmentation. A crucial question relevant on both accounts relates to employment. If labor which is set free due to outsourcing remains permanently unemployed, there is a clear case for a defensive policy stance, even from an efficiency point of view, trying in one way or another to prevent or restrict outsourcing. But whether such unemployment is permanent is not exogenous to policy. Much depends on labor market institutions, hence policy should not simply equate jobs lost to outsourcing with a rise in unemployment and a loss in output. The relevant question to ask is whether, under

\footnotetext{
${ }^{2}$ For empirical studies, see Irwin (1996), Feenstra \& Hanson (1996,1997,1999), Feenstra (1998), Hummels et al. (1998,2001), and several papers in Arndt \& Kierzkowski (eds., 2001). In this literature, the terms fragmentation, outsourcing, international disintegration of production, or vertical specialization sometimes have different meanings, but for the present purpose I use them interchangeably.
} 
given labor market institutions, alternative employment of the resources set free through outsourcing generates value-added which fully compensates for the value-added that is lost to outsourcing. If the answer is yes, then the economy (or region) as a whole gains.

This paper looks into this question, assuming a perfect labor market and using the wellknown specific factors model pioneered by Jones (1971). That model is well established as a powerful work-horse to address distributional issues. As will become apparent below, it proves a very valuable tool also for the aforementioned efficiency question, while retaining its distributional insights. The setup is one where international fragmentation is driven by a foreign location advantage due to relatively cheap labor. I will show that if international fragmentation takes place without any element of non-convexity in production, then it causes an efficiency gain which is analogous to the so-called immigration surplus of inward migration. However, contrary to immigration, and in contrast to a widespread view on globalization, with outsourcing there is no positive relationship between the magnitude of that gain and the amount of pain that comes in the form of potentially troublesome income distribution. Instead, the larger the gain, the more moderate the redistribution effect. I will then show that, even under a well-functioning labor market bar of any rigidities, outsourcing may cause an efficiency loss, if technology features a specific form of non-convexity. The non-convexity considered is one where the specific factor used in the disintegrated component of value-added is a fixed input. I shall identify the crucial conditions responsible for whether or not the negative welfare result obtains. Among the surprising results, we find that these conditions are more likely to be met if the wage gap between the domestic and the foreign economy is small. This is in contrast to the often held view that outsourcing poses a particular threat if this gap is large. However, the smaller this gap, the more likely will outsourcing cause the domestic wage rate to even fall below the foreign wage rate. I shall analyse international fragmentation as a two-stage game, whereby in stage one firms decide on where to locate their specific asset, and in stage two they choose optimal employment of domestic and foreign labor. The model endogenously determines the domestic wage rate and the share of domestic firms choosing a fragmented production mode. 


\section{A basic model of international fragmentation}

A defining feature of international fragmentation is that it allows firms to draw on cheaper foreign factors for certain fragments of their value-added process. Outsourcing such fragments to foreign factor markets makes production less costly and should, therefore, mandate higher returns do domestic factors as a whole. However, the reallocation of domestic factors attendant upon such outsourcing will normally imply unequal domestic factor price effects, and under certain conditions it may also imply an overall welfare loss. This section sets the stage for our analysis by first characterizing a general equilibrium for a case where fragmentation is a technological possibility, but does not arise for a lack of economic incentives. Introducing such incentives in the form of lower costs of international fragmentation gives rise to a new domestic equilibrium, the details of which depend on the precise circumstances under which fragmentation takes place. Subsequent sections will explore these details and investigate the welfare and distributional aspects of international fragmentation by means of a comparative static analysis of the two equilibria.

Fragmentation is easier in some sectors than in others. Suppose, therefore, that the domestic economy features two sectors, each using mobile labor and specific capital, and each facing a given price for its output on perfectly competitive world markets. By assumption, fragmentation is possible only in sector 1 where technology is described by the following separable production function:

$$
Y^{1}=Y^{1}\left[F_{A}^{1}\left(L_{A}^{1}, \bar{K}_{A}^{1}\right), F_{B}^{1}\left(L_{B}^{1}, \bar{K}_{B}^{1}\right)\right]
$$

where $F_{A}^{1}$ and $F_{B}^{1}$ denote two fragments, and $L$ and $K$ denote labor and capital. Production in sector 2 satisfies $Y^{2}=Y^{2}\left(L^{2}, \bar{K}^{2}\right)$. I assume, to start with, that all production functions are concave. Non-convexities in sector 1 will be considered in the next section. ${ }^{3}$ A bar indicates exogenously given quantities, capital stocks are sector-specific, and in sector 1 also specific to individual fragments.

\footnotetext{
${ }^{3}$ Equation 1 stipulates a "smoother" technology than is often assumed in the literature on fragmentation and multinational firms. The advantage of this approach is that we may rely on methods of calculus to a larger extent than would otherwise be the case. The underlying technology here is similar to that in Kohler (2001), but I explore a different and somewhat richer set of conditions under which outsourcing takes place.
} 
Treating good 2 as the numéraire, and using $\bar{p}^{1}$ to denote the relative price of good 1 and $w$ for the domestic wage rate, employment in the two industries is governed by the following first-order conditions, where subscripts $j=A, B$ and $L$ denote partial derivatives:

$$
\begin{aligned}
w & =\bar{p}^{1} Y_{j}^{1}\left[F_{A}^{1}\left(L_{A}^{1}, \bar{K}_{A}^{1}\right), F_{B}^{1}\left(L_{B}^{1}, \bar{K}_{B}^{1}\right)\right] \times F_{j L}^{1}\left(L_{j}^{1}, \bar{K}_{j}^{1}\right), \quad j=A, B \\
w & =Y_{L}^{2}\left(L^{2}, \bar{K}^{2}\right) .
\end{aligned}
$$

These conditions require the usual equality between the wage rate and the marginal valueproductivity of labor in all possible employments. Notice that the two fragments in sector 1 are treated separately in 2 . Since we shall not consider changes in final goods prices, we may assume for simplicity that $\bar{p}^{1}=1$.

The two conditions 2 can be solved for $L_{A}^{1}$ and $L_{B}^{1}$ to yield two labor demand curves $L_{A}^{1}=V_{A}^{1}\left(w, \bar{K}_{A}^{1}, \bar{K}_{B}^{1}\right)$ and $L_{B}^{1}=V_{B}^{1}\left(w, \bar{K}_{A}^{1}, \bar{K}_{B}^{1}\right)$. These give profit-maximizing employment of labor in the two fragments of sector 1 as functions of the common wage rate and the fragment-specific capital stocks. They are downward-sloping in $w$, of course, and increasing in both capital stocks. Using $V^{2}\left(w, \bar{K}^{2}\right)$ for the labor demand curve in sector 2 , we obtain the equilibrium wage rate $w^{*}$ from

$$
\bar{L}=V_{A}^{1}\left(w, \bar{K}_{A}^{1}, \bar{K}_{B}^{1}\right)+V_{B}^{1}\left(w, \bar{K}_{A}^{1}, \bar{K}_{B}^{1}\right)+V^{2}\left(w, \bar{K}^{2}\right),
$$

where $\bar{L}$ denotes the given domestic labor endowment. I shall now write $V^{1}\left(w, \bar{K}_{A}^{1}, \bar{K}_{B}^{1}\right)=$ $V_{A}^{1}\left(w, \bar{K}_{A}^{1}, \bar{K}_{B}^{1}\right)+V_{B}^{1}\left(w, \bar{K}_{A}^{1}, \bar{K}_{B}^{1}\right)$ for overall labor demand by industry 1 under integrated production, the term integrated meaning that both fragments are produced drawing on the same (domestic) labor market. In other words, the equilibrium wage rate $w^{*}$ relates to a case where there is no international fragmentation of production. We shall use $\eta_{j}^{1}$ and $\eta^{2}$ to denote the elasticities of $V_{j}^{1}$ and $V^{2}$ with respect to $w$. Inserting $w^{*}$ back into the first order conditions 2 and 3 , we obtain equilibrium employment levels $L^{1 *}=L_{A}^{1 *}+L_{B}^{1 *}$ and $L^{2 *}=\bar{L}-L^{1 *}$.

The situation is depicted in the usual way by figure 1, where the possibility of fragmentation is brought to the fore by drawing $V_{B}^{1}$ with its origin placed at $L_{A}^{1 *}$. Equilibrium output in industry 1 is measured, in value terms, by the area $A^{1} B L^{1 *} 0^{1}$ or, equivalently, by the sum of areas $A^{1} B_{A}^{1} L_{A}^{1 *} 0^{1}$ (value generated by fragment $A$ ) and $A_{B}^{1} B L^{1 *} L_{A}^{1 *}$ (value generated by fragment $B$ ). It should be borne in mind, however, that each of the two marginal product schedules $V_{j}^{1}$ is subject to the other fragment being available in the 
optimal amount. This makes the case fundamentally different from a simple tree-sector model.

I now turn to international fragmentation, assuming that outsourcing is restricted to fragment $B$. It is quite obvious from the introduction that international fragmentation bears a close resemblance to multinational firms, or foreign direct investment of the vertical type. Indeed the conceptual framework often used in the theory of multinational firms serves quite well to describe the nature and driving force of what I mean by the process of international fragmentation in this paper. The framework involves the celebrated trinity of ownership advantage, location advantage, and internalization advantage. ${ }^{4}$ I assume that $\bar{K}_{B}^{1}$ confers an ownership advantage to domestic firms. We interpret $\bar{K}_{B}^{1}$ as a capital stock, but it could actually be any asset conferring such an ownership advantage; see Markusen (2002). The crucial point is that such an advantage rules out any foreign production of fragment $B$, independent of domestic sector 1 firms. Moreover, international fragmentation requires that the asset $\bar{K}_{B}^{1}$, or its services, be transferred to fragment $B$ production facilities abroad. In other words, fragmentation arises with foreign direct investment.

I assume that there is a neighboring country which enjoys a location advantage with respect to fragment $B$, based on a relatively low wage rate. I do not model this neighboring economy explicitly, but simply assume that its wage rate is given. Moreover, I assume that there are prohibitive barriers to labor migration. For the initial equilibrium described above, I assume that additional costs of transport and communication involved in cross-border vertical fragmentation of production nullify this location advantage, whence fragmentation does not take place. The easiest interpretation is to assume that all such costs arise in the form of additional labor. Thus, assuming that foreign production of fragment $B$ requires $1+t$ units of labor for each effective unit of labor input, an effective location advantage for international fragmentation arises if, due to a fall in $t$, we observe $w^{f}=w^{n}(1+t)<w^{*}$, where $w^{n}$ is the given wage rate in the neighboring country. ${ }^{5}$ It

\footnotetext{
${ }^{4}$ See Markusen (2002) for a modern treatment of this conceptual framework.

${ }^{5}$ The theory of the vertical multinational firm usually assumes that the location advantage is based on different factor intensities of different stages of production; see Markusen (2002). Assuming that outsourcing is restricted to fragment $B$ can be interpreted along such lines, although for simplicity I do not model it explicitly.
} 
should be noticed that fragment $B$ is part of a two-stage production process, deriving its economic value from production according to $Y^{1}\left[F_{A}^{1}\left(L_{A}^{1}, \bar{K}_{A}^{1}\right), F_{B}^{1}\left(L_{B}^{1}, \bar{K}_{B}^{1}\right)\right]$. Fragmentation, thus, is of the vertical type where low international barriers work in favor of a foreign location advantage, as opposed to horizontal FDI. ${ }^{6}$ It is important that the ownership advantage of domestic firms only applies in relation to the neighboring country. Therefore, despite this advantage, domestic firms behave competitively on the world market where they face a given price for good 1. Put differently, the domestic and the neighboring foreign country are jointly small on world markets. Moreover, although one could make the stages of production explicit, it does not make any fundamental difference for our analysis whether we look at fragment $B$ as a "downstream" or "upstream" activity. ${ }^{7}$

The location advantage still leaves open whether fragmentation is carried out by means of arm's-length transactions with foreign subcontractors, or internally within domestic firms' own hierarchies. For our purposes, this doesn't really matter, but as pointed out by Markusen (2002, p.20), transferring assets relevant for the ownership advantage at arm's length will typically run the risk of "asset dissipation". This, in turn, confers an advantage to internalization and it seems reasonable to assume that fragmentation occurs with the emergence of multinational firms. But, as I said, the crucial element of the present approach is the ownership advantage as such, and not internalization.

With $w^{f}<w^{*}$, returns to fragment-B-type capital $K_{B}^{1}$ may obviously be increased by vertical fragmentation. Profit-maximizing firms will start investing part of their given assets $\bar{K}_{B}^{1}$ in the neighboring country, thereby shifting from integrated production to production under vertical fragmentation. What does the new equilibrium look like? Comparing this equilibrium with the case where the costs of fragmentation nullify the location advantage, what are the welfare and distribution effects of vertical fragmentation? In this section, I address these questions for the case where $F_{B}^{1}\left(L_{B}^{1}, \bar{K}_{B}^{1}\right)$ is concave. In particu-

\footnotetext{
${ }^{6}$ Markusen (2002) demonstrates in a comprehensive analysis that the recent upsurge of foreign direct investment is pedominantly horizontal in nature, if looked at from a worl-wide perspective. But he explicitly acknowledges the importance of vertical FDI for many countries and industries. On the other hand, one frequently finds studies claiming and documenting the particular significance of intermediates in recent trade developments; see Jones (2000) and several of the studies mentioned in the introduction.

${ }^{7}$ One could, for instance, treat fragment $A$ as an upstream semi-finished good which may be shipped abroad where fragment $B$ involves further processing and assembly. The final good may then be shipped back to the sales departments in the home country.
} 
lar, what I rule out is any indivisibility with respect to assets $\bar{K}_{B}^{1}$, meaning that vertical fragmentation may take place by outsourcing arbitrarily small amounts of fragment $B$. The subsequent section will look at a case where $\bar{K}_{B}^{1}$ is subject to a specific type of indivisibility.

I use a tilde to indicate equilibrium values under vertical fragmentation. As firms in sector 1 can now procure fragment $B$ by drawing on foreign labor for a given wage rate $w^{f}<w^{*}$, it is clear that $\tilde{w}<w^{*}$. It seems that the distributional implication of vertical fragmentation is almost trivial: labor loses and capital owners in sector 1 gain. However, exploring the new equilibrium in more detail reveals further interesting insights.

A first important point to note is that, even if vertical fragmentation is not subject to any indivisibility, it need not pull the domestic wage rate all the way down to $w^{f}$. In other words, outsourcing is a rather limited form of indirect integration of labor markets. This is due to technology in sector 1 which implies that outsourcing of fragment $B$ also affects domestic labor demand for fragment $A$. With vertical fragmentation, employment in the two fragments of sector 1 are governed by the following two equations:

$$
\begin{aligned}
w & =Y_{A}^{1}\left[F_{A}^{1}\left(L_{A}^{1}, \bar{K}_{A}^{1}\right), F_{B}^{1}\left(L_{B}^{1}, \bar{K}_{B}^{1}\right)\right] \times F_{A L}^{1}\left(L_{A}^{1}, \bar{K}_{A}^{1}\right) \\
w^{f} & =Y_{B}^{1}\left[F_{A}^{1}\left(L_{A}^{1}, \bar{K}_{A}^{1}\right), F_{B}^{1}\left(L_{B}^{1}, \bar{K}_{B}^{1}\right)\right] \times F_{B L}^{1}\left(L_{B}^{1}, \bar{K}_{B}^{1}\right)
\end{aligned}
$$

Notice that these equations do not imply that domestic labor faces different wages in equilibrium. The point is that $L_{B}^{1}$ must not be equated with domestic employment. Indeed, only if the equilibrium wage rate $\tilde{w}$ is equal to $w^{f}$ will equilibrium employment $\tilde{L}_{B}^{1}$ partly also involve domestic employment. Conversely, if $\tilde{w}>w^{f}$, then $\tilde{L}_{B}^{1}$ will entirely be foreign labor. A case where $\tilde{w}<w^{f}$ is, of course, ruled out in equilibrium since firms would face an incentive to replace domestic for foreign employment at the margin on fragment $B$. If such replacement can only occur subject to indivisibilities pertaining to the fragment $B$ asset $\bar{K}_{B}^{1}$, then things are different, as we shall see in the subsequent section.

Whether or not the case $\tilde{w}>w^{f}$ arises depends on general equilibrium interactions with sector 2 where employment is still governed by condition 3 . It is convenient to work with reduced form labor demand functions derived from 5 and 6 . Solving these equations for $L_{A}^{1}$

$$
\tilde{L}_{A}^{1}=\tilde{V}_{A}^{1}\left(w, w^{f}, \bar{K}_{A}^{1}, \bar{K}_{B}^{1}\right)
$$

which gives domestic employment levels in fragment $A$ for alternative domestic wage 
rates $w$, always assuming optimal response of employment (whether domestic or foreign) on fragment $B$ at the wage rate $w^{f}$, which can in turn be described by the corresponding solution of 5 and 6 for $L_{B}^{1}:{ }^{8}$

$$
\tilde{L}_{B}^{1}=\tilde{V}_{B}^{1}\left(w, w^{f}, \bar{K}_{A}^{1}, \bar{K}_{B}^{1}\right)
$$

Notice that $\tilde{V}_{A w^{f}}^{1}<0$, since a higher foreign wage rate lowers foreign employment and thus the marginal productivity of domestic labor in fragment $A$. For a similar reason, $\tilde{V}_{B w}^{1}<0$. Defining $\omega=w^{f} / w^{*}-1$ as the percentage wage gap between the two neighboring economies then, the condition under which vertical fragmentation leads to a wage rate $\tilde{w}>w^{f}$ may be approximated by

$$
L_{A}^{1 *} \eta_{A}^{1} \omega+L^{2 *} \eta^{2} \omega>L_{B}^{1 *}
$$

where a star indicates employment levels in the initial equilibrium, and where $\eta_{A}^{1}$ and $\eta^{2}$ are elasticities of $V_{A}^{1}$ and $V^{2}$, as defined above, evaluated at $w^{*} .{ }^{9}$ The left-hand side gives the additional employment arising in fragment $A$ of industry 1 and industry 2, if the domestic wage rate were to fall down to $w^{f}$. If this is larger than the employment lost due to outsourcing, then domestic labor market equilibrium requires $\tilde{w}>w^{f}$. Notice that by construction of our argument $\omega<0$, and assuming normal labor demand schedules $\eta_{A}^{1}$ and $\eta^{2}$ are also negative. Condition 9 may be rewritten as

$$
|\omega|^{-1}<\frac{L_{A}^{1 *}}{L_{B}^{1 *}}\left|\eta_{A}^{1}\right|+\frac{L^{2 *}}{L_{B}^{1 *}}\left|\eta^{2}\right| .
$$

If this condition is met, then outsourcing, or the international division of labor on the level of fragments, is complete. For given labor demand elasticities, the wage gap must exceed a critical level, for this to arise. Conversely, for a given wage gap, if labor demand elasticities in the "non-outsourcing" activities and their initial employment levels,

\footnotetext{
${ }^{8}$ Comparing these schedules with $V_{A}^{1}$ and $V_{B}^{1}$ which rule out vertical fragmentation, we observe that $\tilde{V}_{A}^{1}\left(w, w^{f}, \bar{K}_{A}^{1}, \bar{K}_{B}^{1}\right)>V_{A}^{1}\left(w, \bar{K}_{A}^{1}, \bar{K}_{B}^{1}\right)$ and $\tilde{V}_{B}^{1}\left(w, w^{f}, \bar{K}_{A}^{1}, \bar{K}_{B}^{1}\right)<V_{B}^{1}\left(w^{f}, \bar{K}_{A}^{1}, \bar{K}_{B}^{1}\right)$ if $w>w^{f}$, with equality obtaining if $w=w^{f}$. Conversely, if $w<w^{f}$, we have the opposite inequalities, but this case of course begs the question of why fragment $B$ is not moved back to the domestic economy. We shall return to this in the subsequent section.

${ }^{9}$ This is an approximation, because we apply a discrete wage difference to the labor demand elasticities which need not be constant. Moreover, since $V_{A}^{1}\left(w^{f}, \bar{K}_{A}^{1}, \bar{K}_{B}^{1}\right)=\tilde{V}_{A}^{1}\left(w^{f}, w^{f}, \bar{K}_{A}^{1}, \bar{K}_{B}^{1}\right)$, the change from $V_{A}^{1}\left(w^{*}, \bar{K}_{A}^{1}, \bar{K}_{B}^{1}\right)$ to $\tilde{V}_{A}^{1}\left(w^{f}, w^{f}, \bar{K}_{A}^{1}, \bar{K}_{B}^{1}\right)$ may be approximated by $L_{A}^{1 *} \eta_{A}^{1} \omega$.
} 
relative to the incipient employment loss from outsourcing, are sufficiently large, then the domestic wage rate will not fall all the way down to $w^{f}$, and there will be no domestic employment in fragment $B .{ }^{10}$ Notice that it is only when the domestic economy loses all of fragment $B$ entirely that some of the initial wage gap remains. This may seem counter-intuitive to the layman, but it is what trade theory leads us to expect: complete vertical specialization is consistent with a wage difference, while incomplete specialization implies wage equalization.

Notice also that incomplete vertical specialization also implies that FDI is similarly incomplete, with part of $\bar{K}_{B}^{1}$ invested abroad and the rest domestically. The condition which governs this margin requires that the rental obtained on both types of investment must be the same. With homothetic technology, the shares of domestic employment and domestic investment in fragment $B$ are the same.

Figure 1 depicts a case where condition 10 is violated and where, therefore, the vertical fragmentation equilibrium features $\tilde{w}=w^{f}$. Domestic employment in fragment $A$ is at $\tilde{L}_{A}^{1}$, while sector 2 employs $\tilde{L}^{2}$ (measured from $O^{2}$ ), both at the equilibrium wage rate $\tilde{w}=w^{f}$. Total employment in fragment $B$ is equal to the difference between overall labor use by sector 1 firms, $\tilde{L}^{1}$ (measured from $O^{1}$ ), and $\tilde{L}_{A}^{1}$. Of this labor use, also measured by $\tilde{L}_{B}^{1}$ (with origin at $L_{A}^{1 *}$ ), $\tilde{L}_{B f}^{1}$ is foreign labor, while $\tilde{L}_{B}^{1}-\tilde{L}_{B f}^{1}$ is domestic labor, whereby it is evident that $\tilde{L}_{B}^{1}-\tilde{L}_{B f}^{1}+\tilde{L}_{A}^{1}+\tilde{L}^{2}=\bar{L}$ (full employment).

Figure 1 allows us to identify the welfare effect of vertical fragmentation. We must first note that domestic labor suffers an income loss equal to $\left(w^{*}-\tilde{w}\right) \bar{L}$, all of which ends up as additional income to capital owned by domestic firms. In addition, however, domestic capital owners gain on infra-marginal units of re-allocated domestic labor, and on foreign labor. More specifically, the labor initially set free through outsourcing, once reallocated towards alternative domestic use, generates additional value-added in fragment $A$ equal to the area $B_{A}^{1} \tilde{B}_{A}^{1} \tilde{L}_{A}^{1} L_{A}^{1 *}$, and additional output in industry 2 equal to the area $B \tilde{B}^{2} \tilde{L}^{2} L^{1 *}$. In addition, domestic and foreign labor taken together generate additional value-added in fragment $B$, measured by the area $B \tilde{B}_{B}^{1} \tilde{L}_{B}^{1} L^{1 *} \cdot{ }^{11}$ Netting out the labor

\footnotetext{
${ }^{10} \mathrm{~A}$ similar thrust is also emerging from the general analysis of distributional effects in Kohler (2003), where it is shown that the factor price effects are importantly driven by the production characteristics of the domestic "non-outsourcing" activities.

${ }^{11}$ Note that the distance $\tilde{L}_{A}^{1} \tilde{L}^{1}$ is equal to the distance $L_{A}^{1 *} \tilde{L}_{B}^{1}$.
} 
income which is lost on previous domestic production of fragment $B$ (and which does not show up as redistributed income to capital), i.e., subtracting $B_{A}^{1} B L^{1 *} L_{A}^{1 *}$, we arrive at a net welfare gain to the domestic economy which is measured by the compound shaded triangles indicated in figure 1. The welfare gain is somewhat less straightforward to measure diagrammatically, if outsourcing is complete and $\tilde{w}>w^{f}$, but essentially similar logic can be applied to establish a clear welfare gain also in this case.

This analysis is reminiscent of the well-known immigration surplus; see Borjas (1999). After all, outsourcing in this model is an indirect way of drawing on foreign labor. It is well known that the immigration surplus arises if foreign labor is employed according to a downward sloping marginal product curve and is paid its marginal product. ${ }^{12}$ In our case, what guarantees a "vertical fragmentation surplus" comparable to the immigration a surplus is the presence specific factors. There is an important difference, however. While the immigration surplus approaches zero if the domestic labor demand schedule becomes flat, as in the case of Rybczynski-type domestic reallocation, the outsourcing surplus arising here is the larger, the larger the elasticities of labor demand in the alternative domestic employment of labor. This is readily seen from figure 1, where the overall shaded area increases in size, if the slopes of $V_{A}^{1}$ and $V^{2}$ fall in absolute value. The difference is easily explained. The immigration surplus as usually portrayed assumes an exogenously given labor inflow, with wages adjusting endogenously. Here, we assume an exogenous wage differential $w^{*}-w^{f}$ to start with, and the quantity adjustments (extent of outsourcing as well as domestic labor re-allocation) follow endogenously.

Putting the results obtained so far into a broader perspective, we identify an important message. It is widely acknowledged that globalization may hold significant efficiency gains, but there is equally widespread concern that such gains may be associated with painful redistribution. Moreover, it is often argued that the larger the gains, the larger the pains. ${ }^{13}$ Somewhat surprisingly, outsourcing in the present context is a form of global-

\footnotetext{
${ }^{12}$ There are several ways in which this may arise, an important point being whether the mix of factor inflows is any different from the mix of domestic endowment; see Borjas (1999). Notice, however, that Rybczynski-type internal factor reallocation may allow the domestic economy to employ additional labor at a constant marginal productivity, in which case no surplus will arise. It is interesting to compare this to the general result on distributional effects from fragmentation derived in Kohler (2003), where the factor intensity pattern of outsourcing relative to the domestic endowment similarly plays a key role.

${ }^{13}$ See Rodrik (1998) who emphasizes that gains from trade require restructuring and that restructuring
} 
ization where this tension does not arise. Indeed, it is evident from figure 1 that the larger the gain from international outsourcing, the lower the redistribution effect in the form of lower wage income. Suppose, for instance, that labor demand in sector 2 is perfectly elastic. Taking the non-fragmentation equilibrium with $w^{*}$ as a reference point, the vertical fragmentation equilibrium then implies $\tilde{w}=w^{*}$, with $\tilde{L}_{A}^{1}=\tilde{V}_{A}^{1}\left(w^{*}, w^{f}, \bar{K}_{A}^{1}, \bar{K}_{B}^{1}\right)$ and $\tilde{L}^{2}=\bar{L}-\tilde{L}_{A}^{1}$. Moreover, there will be complete outsourcing of fragment $B$ with foreign labor use equal to $\tilde{L}_{B}^{1}=\tilde{V}_{B}^{1}\left(w^{*}, w^{f}, \bar{K}_{A}^{1}, \bar{K}_{B}^{1}\right)$. There is no domestic wage depression from international fragmentation. At the same time, in a figure analogous to 1 , our logic finds that the welfare gain rises to include the full rectangle $B_{A}^{1} B D C$, plus a triangle corresponding to $B \tilde{B}_{B}^{1} D$, with the point $\tilde{B}_{B}^{1}$ shifted to the left, reflecting employment along the schedule $\tilde{V}_{B}^{1}\left(w^{*}, w^{f}, \bar{K}_{A}^{1}, \bar{K}_{B}^{1}\right)$ instead of $V_{B}^{1}\left(w^{f}, \bar{K}_{A}^{1}, \bar{K}_{B}^{1}\right)$. From this extreme case it is easily seen that in this model, contrary to widespread belief about globalization effects, the redistribution effects from international fragmentation are the lower the larger the efficiency gains. ${ }^{14}$

\section{Indivisibility and "discrete outsourcing"}

The preceding analysis has an odd feature: If out sourcing is incomplete in the vertical fragmentation equilibrium, then all firms in sector 1 produce fragment $B$ both at home and abroad. This is odd because the driving forces behind vertical FDI normally assumed in the theory of multinational firms are such that the equilibrium involves a coexistence of different types of firms - purely domestic firms and vertical multinationals, say - but no firms doing the same stage both at home and abroad. The reason, of course, is the assumed presence of scale economies. The FDI literature often stipulates some variant of fixed cost on the plant-level and/or the firm-level, and then determines the equilibrium number of

\footnotetext{
is likely to have distributional impacts. Moreover, he argues that “... if the distributional impacts have been small, the net gains have been small in all likelihood as well". In Rodrik (1997), he reports on estimates indicating that $5 \$$ of income get redistributed for every $1 \$$ of net welfare gains from trade.

${ }^{14}$ It should be noted, however, that even in the extreme case above, although there is no domestic wage depression, there is still redistribution in that income to capital owners in sector 1 have risen. This is a case where a redistribution effect is present, but it satisfies the criterion of Corden's "conservative social welfare function".
} 
different types of firms by assuming a free-entry-zero-profit equilibrium; see Markusen (2002). In this section, I shall re-interpret the above model towards the presence of fixed cost. However, instead of assuming free-entry, I assume a given number $n$ of domestic firms and look at the question of how these firms respond to a fall in the costs of vertical fragmentation by allocating their fixed assets for fragment $B$ at home or abroad. On the firm-level, then, outsourcing will always be complete - if the firm goes for fragmentation at all. But the industry as a whole may well exhibit both, purely domestic firms and firms producing in a fragmented manner. We denote the number of fragmented firms by $n^{f}$ and their fraction by $\nu \equiv n^{f} / n$. I will show that, from an economy-wide perspective, the two most important consequences of allowing for fixed costs are a) that vertical fragmentation induced by lower effective foreign cost of labor may lower domestic welfare and b) that the domestic wage rate may fall below the foreign wage rate.

Suppose that production of fragment $B$, whether carried out at home or abroad, requires a fixed amount $\bar{k}_{B}^{1}$ of capital which is specific to sector 1 and fragment $B$. As indicated above, $\bar{k}_{B}^{1}$ could also be interpreted as some other asset whose service is required to support production of fragment $B$ with a variable input of labor. The important point is that it confers an ownership advantage to domestic firms. ${ }^{15}$ Given the presence of this asset, the marginal productivity of labor is diminishing, giving rise to downward-sloping labor demand functions for each firm. In order to link the analysis to the previous section, I assume that $n \bar{k}_{B}^{1}=\bar{K}_{B}^{1}$, where all firms are symmetric. Moreover, I assume that the marginal productivity of labor in terms of fragment $B$ can be described by a function $F_{B l}^{1}\left(\bar{k}_{B}^{1}, l_{B}^{1}\right)$, where $l_{B}^{1}$ denotes firm-level employment.

Fixed costs imply a non-convex technology, and this begs the question of whether perfect competition remains a reasonable assumption. I assume that the fixed cost involved in fragment $B$ is not "too large", relative to overall cost and world demand, so that a long-run, free entry equilibrium of the world market features a sufficiently large number

\footnotetext{
${ }^{15}$ The interpretation of fixed costs can be one of firm-level or plant-level scale economies. In the former case, the underlying assumption is that the firm may geographically separate of the asset and the plant, but where the asset can serve only one plant - either domestic or foreign. In the latter case the asset itself must be transferred to the foreign plant. Assumptions like these are often relied to separate theoretical paradigms for vertical and horizontal FDI (see Markusen, 2002), but since our model is entirely geared towards vertical fragmentation anyway, the reader is free to choose whatever may seem a more satisfactory interpretation.
} 
of firms, world-wide, for each of them to perceive a given world price for its final output. Moreover, to start with, I assume that industry 1 firms have no market power on on the domestic labor market where they compete with industry 2. We will, however, see that vertical fragmentation may confer a certain amount of market power on firms in sector 1 .

\subsection{The single firm case}

We first look at the easiest case where $n=1$, starting out with an appropriate reinterpretation of figure 1. Employment in fragment $A$ is at $\tilde{B}_{A}^{1}$ while, due to the underlying indivisibility of the relevant asset $\bar{k}_{B}^{1}$, the firm produces all of fragment $B$ abroad, with a profit maximizing foreign labor input equal to the distance $\tilde{B}_{A}^{1} \tilde{B}$. Since industry 2 is at point $\tilde{B}^{2}$, there is excess supply on the domestic labor market equal to $\tilde{B}_{A}^{1} \tilde{B}^{2}$, which pulls the domestic wage down to an equilibrium value $\tilde{w}<w^{f}$. As the wage falls below $w^{f}$, the firm increases its domestic labor demand according to the schedule $\tilde{V}_{A}^{1}$, defined in 7 , and its foreign labor demand on fragment $B$ moves from $\tilde{B}$ to $\tilde{E}^{1}$., in line with $\tilde{V}_{B w}^{1} \cdot \mathrm{d} w$, where $\tilde{V}_{B}^{1}$ is defined in 8 above. Notice that all domestic labor is paid a uniform wage rate $\tilde{w}$, but the domestic firm pays a higher wage rate for foreign labor. Shouldn't this be an incentive for the domestic firm to withdraw, or abstain, from international fragmentation? The answer is no, if the firm anticipates that by investing its asset $\bar{k}_{B}^{1}$ at home would immediately move the economy back to $B$, where its profits are clearly lower. In a sense, since vertical fragmentation is an option to a single firm, and since it may only take place in discrete amounts, this firms obtains "quasi-market-power" on the domestic labor market in that it can influence the domestic wage rate. Market power is, however, limited, since there are only two possible outcomes, $\tilde{w}$ and $w^{*}$, among which this firm can choose.

In the case depicted by figure 2, this scenario of vertical fragmentation involves an overall welfare loss for the home economy. The reason is that there is triangular loss, in addition to the positive welfare triangles familiar from figure 1 above. Domestic labor which is reallocated from domestic production of fragment $B$ to fragment $A$ and industry 2 , respectively, generates less value-added than it did before. Prior to this reallocation, it has received income equal to the rectangle $B_{A}^{1} B L^{1 *} L_{A}^{1 *}$. Now, its income has fallen to $C^{\prime} D^{\prime} L^{1 *} L_{A}^{1 *}$ which is equal to $\left(L^{1 *}-L_{A}^{1 *}\right) \tilde{w}$. The difference is not completely offset by the immediate cost-savings effect of outsourcing measured by the area $B_{A}^{1} B D C$, plus the additional capital income generated on infra-marginal labor now employed in industry 2 and 
fragment $A$, equal to the sum of the areas $B \tilde{E}_{A}^{1} D^{\prime}$ and $B_{A}^{1} \tilde{B}_{A}^{1} \tilde{E}_{A}^{1} C^{\prime}$. International fragmentation is beneficial only if the triangle $\tilde{B}_{A}^{1} \tilde{B}^{2} \tilde{E}_{A}^{1}$ is smaller in size than the compound triangular gain identified in the simpler case above.

Such a loss can, however, only arise if condition 10 is violated. Another way to look at this condition which may shed more light on the issue is to use employment shares $\lambda_{A}^{1}=L_{A}^{1 *} /\left(L_{A}^{1 *}+L^{2 *}\right)$ and $\lambda^{2}=1-\lambda_{A}^{1}$ for all those activities that - for whatever reason are not amenable to outsourcing. In our case these "non-outsourcing activities" are sector 2 and fragment $A$ of sector 1 . Condition 10 can then be reformulated to

$$
\frac{\left(L_{A}^{1 *}+L^{2 *}\right)\left(w^{*}-w^{f}\right)}{w^{*} L_{B}^{1 *}}>\frac{1}{\lambda_{A}^{1}\left|\eta_{A}^{1}\right|+\lambda^{2}\left|\eta^{2}\right|} .
$$

The left-hand side of 11 measures the "would-be-cost-effect" of the wage gap if applied to the initial levels of the "non-outsourcing activities", relative to the initial wage cost of the "outsourcing activity" which is fragment $B$ in sector 1 . The right-hand side is simply the inverse of the weighted sum, in absolute terms, of labor demand elasticities of the "non-outsourcing activities".

There is an important general lesson from this analysis. Policy discussions often concentrate on the wage-gap $w^{*}-w^{f}$ as a measure of the threat that globalization may pose to high-wage-countries. The present analysis reveals that this is potentially misleading. Conditions 10 and 11 equivalently state that, other things equal, a welfare loss for the domestic economy is less likely if this wage difference is large. Nor is the redistribution effect determined by this gap, as is most easily recognized by simply altering the level of $w^{f}$ in figure 2, keeping all else constant. The welfare loss is rising, but the domestic wage effect remains unaltered. The intuition for this result is quite straightforward. Due to the indivisibility pertaining to $\bar{k}_{B}^{1}$, an arbitrarily small wage gap - with a correspondingly low savings potential from fragmentation - can act as a valve for a heavy incipient loss of domestic employment which will subsequently be re-employed subject to diminishing marginal productivity. ${ }^{16}$

If $n>1$, then issues of strategic interaction are likely to arise in the process of international fragmentation, at least if $n$ is relatively small. However, before turning to

\footnotetext{
${ }^{16} \mathrm{~A}$ similar thrust is also emerging from the general analysis of distributional effects in Kohler (2003), where it is shown that the factor price effects are importantly driven by the production characteristics of the domestic "non-outsourcing-activities".
} 
any specific assumption about firm behavior, I look at the labor market equilibrium that arises under alternative values of $\nu$, the fraction of firms producing in a fragmented mode. Overall domestic labor demand in sector 1 is

$$
\begin{aligned}
\tilde{V}^{1}\left(w, w^{f}, \nu, \bar{K}_{A}^{1}, \bar{K}_{B}^{1}\right) \equiv & (1-\nu) V_{A}^{1}\left(w, \bar{K}_{A}^{1}, \bar{K}_{B}^{1}\right)+\nu \tilde{V}_{A}^{1}\left(w, w^{f}, \bar{K}_{A}^{1}, \bar{K}_{B}^{1}\right) \\
& +(1-\nu) V_{B}^{1}\left(w, \bar{K}_{A}^{1}, \bar{K}_{B}^{1}\right) .
\end{aligned}
$$

Notice that by definition of $\tilde{V}_{A}^{1}$ we have $\tilde{V}_{A}^{1}\left(w^{f}, w^{f}, \bar{K}_{A}^{1}, \bar{K}_{B}^{1}\right)=V_{A}^{1}\left(w^{f}, w^{f}, \bar{K}_{A}^{1}, \bar{K}_{B}^{1}\right)$. Obviously, $\tilde{V}^{1}$ is falling in $w \cdot{ }^{17}$ Moreover, if $V_{B}^{1}>\tilde{V}_{A}^{1}-V_{A}^{1}$, then $\tilde{V}_{A}^{1}$ is falling in $\nu$. This condition necessarily holds for $w<w^{f}$, where fragmented firms have lower labor demand on fragment $A$ than purely domestic firms. This will be the case we are primarily looking at. For a given $\nu, \tilde{V}^{1}$ is falling also in $w^{f}$, the reason being that a higher $w^{f}$ leads all fragmented firms to lower foreign employment on fragment $B$, thereby also reducing the marginal productivity of labor in their domestic fragment $A$ plant.

Labor market equilibrium requires

$$
\tilde{V}^{1}\left(w, w^{f}, \nu, \bar{K}_{A}^{1}, \bar{K}_{B}^{1}\right)+V^{2}\left(w, \bar{K}^{2}\right)=\bar{L},
$$

which can be solved for a market-clearing wage rate

$$
\tilde{w}=\tilde{w}\left(w^{f}, \nu, \bar{K}_{A}^{1}, \bar{K}_{B}^{1}, \bar{K}^{2}, \bar{L}\right) .
$$

The function $\tilde{w}$ is obviously increasing in all capital stocks, while falling in $\bar{L}$ and $\nu$. Somewhat counter-intuitively, it is falling in $w^{f}$, the reason being that, for a given $\nu$, $\tilde{V}^{1}$ is falling in $w^{f}$, as argued above. This should, however, not be interpreted as a complementarity relationship between foreign and domestic labor in general equilibrium. We have not yet established a general equilibrium. The crucial point is that, given the foreign wage rate $w^{f}$, the equilibrium value of $\nu$ depends on the domestic wage rate $\tilde{w}$. More specifically, in addition to 14 , an equilibrium requires that the share of fragmented firms $\nu$ be such that, given the discrepancy between $\tilde{w}$ and $w^{f}$, no firm faces an incentive to switch from one regime (domestic integration) to the other (vertical fragmentation).

Notice that, strictly speaking, $\nu$ cannot be seen as a continuous variable, unless the number of firms $n$ is very large. Moreover, given the underlying indivisibility of $\bar{k}_{B}^{1}, \tilde{V}^{1}$

\footnotetext{
${ }^{17}$ Equation 12 formulates labor demand in such a way that there is a firm relation to the previous section and to figures 1 and 2 .
} 
varies in discrete and potentially large jumps as $\nu$ varies, with associated jumps in the domestic wage rate that clears the labor market in line with 13 . I shall return to this problem below. Here, we may note that, since $V^{2}$ is continuous in $w$, there is a unique wage rate that satisfies 13 for each possible value of $\nu$.

\subsection{Multiple firms: the non-cooperative equilibrium}

Some of the possible equilibria for $n>1$ are easily identified. Suppose, for instance, that the elasticities $\left|\eta_{A}^{1}\right|$ and $\left|\eta^{2}\right|$ are large enough for condition 10 to be met. In terms of figure 2 , this implies that the $V_{A}^{1}$ - and the $V^{2}$-schedules intersect at a wage rate above $w^{f}$. In such a case, a domestic wage rate equal to $w^{f}$ would be associated with excess demand on the domestic labor market, even if all firms are fragmented, $\nu=1$, and even more so if $\nu<1$. Therefore, equilibrium implies $\nu=1$ and $\tilde{w}>w$. All firms produce in fragmented mode and have no incentive to change their strategy. This equilibrium is identical in all respects to the one arising with a perfectly divisible asset. Indivisibility simply doesn't matter, irrespective of the number of firms present in sector 1.

The more interesting case to look at is one where condition 10 is violated, say because labor demand in the "non-outsourcing-activities" is relatively inelastic. Then, a case where all firms are fragmented would give rise to a domestic wage rate $\tilde{w}<w^{f}$. If $n$ is large, such that an individual domestic firm is unaware of its "quasi-market-power" on the domestic labor market, then it treats the domestic wage rate $\tilde{w}$ as given, independent of its own choice of regime. Taking the symmetry assumption to its extreme, if $\tilde{w}<w^{f}$, all firms simultaneously revert to an integrated production mode which gives rise to a domestic wage rate $w^{*}$. But $w^{*}>w^{f}$ constitutes an incentive for fragmentation, and we observe an oscillating equilibrium between $\tilde{w}$ and $w^{f}$. Obviously, this is not a realistic scenario, as it involves repeated shifts from one regime to the other without firms ever learning about the wage effect of these shifts. The more realistic and interesting case, therefore, is one where firms anticipate the wage effects attendant upon shifting from one regime to the other.

If domestic firms, cognizant about these wage effects, behave in a cooperative manner, then we are effectively back to the case of a single firm described above. In the noncooperative case, we must make some assumption about the form of strategic interaction. I assume that each firm takes all other firms' choice of regime (domestic integration versus international fragmentation) as given and considers whether changing its own strategy in- 
creases its profits. The case is perhaps best modeled as a two-stage decision. In stage one, firms decide on whether to invest their assets $\bar{k}_{B}^{1}$ to serve domestic or foreign production of fragment $B$. In stage two, integrated firms choose their profit maximizing employment levels according to $V_{A}^{1}\left(w, \bar{K}_{A}^{1}, \bar{K}_{B}^{1}\right) / n$ and $V_{B}^{1}\left(w, \bar{K}_{A}^{1}, \bar{K}_{B}^{1}\right) / n$, while fragmented firms employ domestic labor according to $\tilde{V}_{A}^{1}\left(w, w^{f}, \bar{K}_{A}^{1}, \bar{K}_{B}^{1}\right) / n$ and foreign labor according to $\tilde{V}_{B}^{1}\left(w, w^{f}, \bar{K}_{A}^{1}, \bar{K}_{B}^{1}\right) / n$. I shall now explore a sub-game perfect equilibrium where each firm anticipates a wage rate $\tilde{w}$ according to 14 to prevail in stage two, when making its investment decision in stage one. In other words, in stage two firms behave competitively in the domestic labor market. Equilibrium thus requires that no firm (whether integrated or fragmented) may expect to increase its profit by shifting to the other regime, taking into account the effect that this shift would have on the domestic wage rate according to 14 .

As noted above, the only interesting case remaining to look at is one where condition 10 is violated and $\tilde{w} \leq w^{f}$ for some interior value of $\nu$ between 0 and 1 . The crucial point is under what conditions such a case is supported as a sub-game perfect equilibrium as described above. This requires that a representative fragmented firm faces no incentive to exploit the domestic wage advantage by returning its asset $\bar{k}_{B}^{1}$ back to the home economy, thus becoming a purely domestic firm, while at the same time a representative domestic has no incentive to become fragmented.

We now look at an arbitrary value of $\tilde{w} \leq w^{f}$. If a fragmented firm shifts to a purely domestic production mode, moving fragment $B$ back to the home economy, it will bid up the domestic wage rate according to 14 , and it will do so by a discrete amount, due to the indivisibility of $\bar{k}_{B}^{1}$. This hurts the firm in its domestic production of fragment $A$. On the other hand, since $\tilde{w} \leq w^{f}$, the firm will benefit from lower wage cost on fragment $B$. If the domestic wage increase is not too high, then overall wage cost per unit of output may be reduced, and the expected return specific capital increased, by a "return-shift" of assets $\bar{k}_{B}^{1}$ back to the home economy. We use $\omega^{r}$ to denote the critical wage increase in percentage terms. In other words, if the domestic wage increase to be expected from a "return-shift" is lower than $\omega^{r}$, then a representative fragmented firm would have an incentive to do so. Obviously, $\omega^{r}$ is the higher, the larger the domestic wage advantage to start with, i.e., the lower the ratio $\tilde{w} / w^{f}$.

Discrete changes notwithstanding, I proceed by approximating the cost-effects from wage changes relying on the familiar "cost-shares-calculus". Using $\tilde{\theta}_{j}^{1}$ to denote the share of fragment $j$ in unit-cost of good 1 , and $\tilde{\theta}_{j L}^{1}$ for the labor share in the unit-cost of fragment 
$j$, respectively, of a fragmented firm, I define $\tilde{\varphi}_{j}^{1}=\tilde{\theta}_{j}^{1} \tilde{\theta}_{j L}^{1}$ as the corresponding fragment- $A$ labor share in unit-cost of good 1. A completely analogous definition holds for $\varphi_{j}^{1}$ with respect to a purely domestic firm. The difference between $\tilde{\varphi}_{j}^{1}$ and $\varphi_{j}^{1}$ is due to fragmented firms paying $w^{f}$ on foreign procurement of fragment $B$, while domestic firms pay $\tilde{w}$ for domestic labor on both fragments. Elasticities of substitution will determine whether $\tilde{\varphi}_{j}^{1}$ is larger, smaller, or equal to $\varphi_{j}^{1}$ if $\tilde{w}<w^{f}$. For log-linear technologies, we have $\tilde{\varphi}_{j}^{1}=\varphi_{j}^{1}$. This seems like an innocuous assumption for the subsequent analysis.

The critical wage increase $\omega^{r}$ is then determined by

$$
\varphi_{A}^{1} \omega^{r}-\varphi_{B}^{1}\left[1-\frac{\tilde{w}}{w^{f}}\left(1+\omega^{r}\right)\right]=0 .
$$

The bracketed term gives the percentage difference between the foreign wage and the wage rate the firm anticipates it will pay on fragment $B$ upon the "return-shift". Notice that by assumption $\tilde{w} / w^{f}<1$. Condition 15 can be rewritten as

$$
\omega^{r}=\frac{\varphi_{B}^{1}}{\varphi_{A}^{1}+\varphi_{B}^{1}\left(\tilde{w} / w^{f}\right)}\left(1-\frac{\tilde{w}}{w^{f}}\right) .
$$

Conversely, if a purely domestic firm shifts to vertical fragmentation, it suffers from a higher foreign wage rate on fragment $B, w^{f}>\tilde{w}$. It may still want to do so, however, if it expects a sufficiently strong wage reduction from a higher $\nu$ according to 14 . Thus, from a purely domestic firm's perspective, there is a critical wage effect, below which a regime shift towards outsourcing fragment $B$ implies an expected reduction in wage-cost per unit of output. Expressed in in percentage terms, we denote this critical level by $\omega^{o}$, and it is determined by

$$
\varphi_{A}^{1} \omega^{o}+\varphi_{B}^{1}\left(\frac{w^{f}}{\tilde{w}}-1\right)=0
$$

The first term gives the benefit from a lower domestic wage, while the second term gives the cost effect from paying a higher foreign wage on fragment $B$. Notice that at $\omega^{o}<0$ if $\tilde{w} / w^{f}<1$ as assumed. We now look the absolute value of the wage effect, rewriting condition 17 as

$$
\left|\omega^{o}\right|=\frac{\varphi_{B}^{1}}{\varphi_{A}^{1}}\left(1-\frac{\tilde{w}}{w^{f}}\right) \frac{w^{f}}{\tilde{w}}
$$

If the domestic wage reduction caused by a domestic firm outsourcing its fragment $B$ is exceeds $\left|\omega^{o}\right|$ in absolute terms, then outsourcing would increase the return to $\bar{k}_{B}^{1}$ and the firm would have an incentive to so so. Since by assumption $w^{f} / \tilde{w}>1$, the right-hand side of 18 is larger than the right-hand side of 16 . Assume for a moment that the two types of 
firms have symmetric views on the wage effects of a regime shift, i.e., the wage effect from a domestic firm becoming fragmented is the same, in absolute terms, as the wage effect from a fragmented firm becoming a purely domestic one. ${ }^{18}$ Then, if a fragmented firm faces an incentive to move back, there cannot not at the same time be an incentive for an integrated firm to move fragment $B$ offshore. By complete analogy, if a domestic firm faces an incentive to become fragmented, then 18 is necessarily violated, hence fragmented firms face no incentive to switch to integrated production.

Figure 3 depicts the two conditions 16 and 18, with $\omega^{r}$ and $\left|\omega^{o}\right|$, respectively, plotted on the vertical, and $\tilde{w} / w^{f}$ on the horizontal axis. Without loss of generality, we may assume $w^{f}=1$, so that we may directly read $\tilde{w}$ off the horizontal axis. From the above discussion, it follows that both lines are downward-sloping and convex. The intuition for line $\Gamma^{r}\left(\tilde{w} / w^{f}\right)$ representing 16 is as follows. Given $\tilde{w} / w^{f}<1$, a fragmented firm pays a higher foreign wage rate and may, therefore, consider moving fragment $B$ back to the domestic economy. However, while the firm thus saves on fragment $B$ wage cost, it will at the same time expect to be negatively affected on fragment $A$, because it bids up the domestic wage by adding a discrete amount of domestic labor demand on fragment $B$. The lower $\tilde{w} / w^{f}$, the larger the savings effect on fragment $B$, the more room, therefore, for the firm to "accommodate" an expected wage increase. Obviously, the line intersects with the horizontal axis at $\tilde{w} / w^{f}$. Moreover, there is a lower bound on $\tilde{w} / w^{f}$ determined by $\nu=1$, i.e., where all $n$ firms are fragmented. A similar intuition holds for the line line $\Gamma^{o}\left(\tilde{w} / w^{f}\right)$ representing 18 . A purely domestic firm has the advantage of a lower domestic wage rate on fragment $B$, but may still consider investing its asset $\bar{k}_{B}^{1}$ abroad, since this lowers the domestic wage rate, with an ensuing cost-savings effect on fragment $A$. The lower $\tilde{w} / w^{f}$, the larger the disadvantage from becoming fragmented, the higher therefore the domestic wage effect, in absolute value, which is necessary to compensate for this in terms of a lower wage on fragment $A$. As with $\Gamma^{r}\left(\tilde{w} / w^{f}\right)$, the line $\Gamma^{o}\left(\tilde{w} / w^{f}\right)$ intersects with the horizontal axis at $\tilde{w} / w^{f}=1$, and from the above discussion, we know that $\Gamma^{o}\left(\tilde{w} / w^{f}\right)>\Gamma^{r}\left(\tilde{w} / w^{f}\right)$ for $\tilde{w} / w^{f}<1$, which is the range we are looking at. Obviously, if there are costs of shifting from one regime to the other, the two lines are farther apart.

To proceed with the analysis, we now turn to the expected wage effects from regime shifts, assuming that each firm considers shifting alone. An obvious, if extreme, assump-

\footnotetext{
${ }^{18}$ Whether or not such symmetry prevails will be discussed below.
} 
tion is that each firm fully internalizes 14 when deriving the wage effect. We approximate the wage effect relying on elasticities of the labor demand schedules appearing in 13 and 12. We denote the relative wage effect attendant upon an isolated "return-shift" by $\hat{\tilde{w}}^{r}$, while the wage effect from an isolated shift to outsourcing is denoted by $\hat{\tilde{w}}^{o}$.

The direct effect on domestic labor demand from a single firm's regime shift of type $r$ is $\Delta^{r} V^{1}=\left(V_{A}^{1}-\tilde{V}_{A}^{1}+V_{B}^{1}\right) / n$, where all labor demands are evaluated at $w=\tilde{w}$ for the given foreign wage rate $w^{f}$. For the other shift we have $\Delta^{o} V^{1}=-\Delta^{r} V^{1}$. Moreover, if $\tilde{w}<w^{f}$ as assumed, then $\Delta^{r} V^{1}>0 . \Delta^{r} V^{1}$ is the discrete analogue to $\tilde{V}_{\nu}^{1} \mathrm{~d} \nu$ in 12 . According to the labor market equilibrium condition 13, the market clearing wage effect of a regime shift of type $r, \Delta^{r} w$, taking place $\tilde{w}$ (with the corresponding value of $\nu$ from 14), can be approximated by

$$
\left(\tilde{V}_{w}^{1}+V_{w}^{2}\right) \Delta^{r} w+\Delta^{r} V^{1}+\frac{1}{n}\left(V_{A w}^{1}-\tilde{V}_{A w}^{1}+V_{B w}^{1}\right) \Delta^{r} w=0
$$

where all labor demand schedules and derivatives are evaluated at $\tilde{w}$ (and the corresponding value of $\nu$ ). This is simply the change in the left-hand side of 13 . Notice the third term which takes into account the second-order effect, reflecting the discrete nature of the labor demand shift that arises from the underlying indivisibility of $\bar{k}_{B}^{1}$. Using labor demand elasticities, this can be rewritten in relative terms as

$$
\left[\eta+\eta_{A}^{1}\left(v_{A}^{1}-\tilde{v}_{A}^{1}\right)+\eta_{B}^{1} v_{B}^{1}\right] \hat{\tilde{w}}^{r}=-\left[\left(v_{A}^{1}-\tilde{v}_{A}^{1}\right)+v_{B}^{1}\right]
$$

where $\hat{\tilde{w}}^{r} \equiv \Delta^{r} w / \tilde{w}$, and $\eta$ indicates the aggregate elasticity of domestic labor-demand $\tilde{V}^{1}+V^{2}$ with respect to $w$, defined as a weighted average of elasticities of the different labor demand schedules according to the definition of $\tilde{V}^{1}$ in 12 , evaluated at $\tilde{w}$. As introduced above, $\eta_{A}^{1}$ and $\eta_{B}^{1}$ denote the elasticities of labor demand $V_{A}^{1}$ and $V_{B}^{1}$, respectively, with respect to $w$. Notice that all elasticities are negative with normal labor demand. Equation 20 assumes for simplicity that $\eta_{A}^{1}=\tilde{\eta}_{A}^{1}$. And finally, lower-case letters indicate the share of an representative firm's labor demand in overall domestic employment, for instance $v_{A}^{1} \equiv V_{A}^{1} / n \bar{L}$ (analogously for $\tilde{v}_{A}^{1}$ and $v_{B}^{1}$ ). Thus, $\left(v_{A}^{1}-\tilde{v}_{A}^{1}\right)+v_{B}^{1}=\Delta^{r} V^{1} / \bar{L}$. Solving 20, we obtain

$$
\hat{\tilde{w}}^{r}=-\frac{\left(v_{A}^{1}-\tilde{v}_{A}^{1}\right)+v_{B}^{1}}{\eta+\eta_{A}^{1}\left(v_{A}^{1}-\tilde{v}_{A}^{1}\right)+\eta_{B}^{1} v_{B}^{1}}>0,
$$

where the inequality follows from $v_{A}^{1}>\tilde{v}_{A}^{1}$ (assuming $\tilde{w} / w^{f}<1$ ) and the assumption of downward-sloping labor demand schedules. 
It is now relatively straightforward to see that an isolated regime switch of type $o$ entails a wage effect equal to

$$
\hat{\tilde{w}}^{o}=\frac{\left(v_{A}^{1}-\tilde{v}_{A}^{1}\right)+v_{B}^{1}}{\eta-\left[\eta_{A}^{1}\left(v_{A}^{1}-\tilde{v}_{A}^{1}\right)+\eta_{B}^{1} v_{B}^{1}\right]}<0,
$$

where the inequality follows in line with the above, additionally assuming that the secondorder effect (second term in the denominator) does not dominate the first-order effect. Looking at the wage effect in absolute terms, we have

$$
\left|\hat{\tilde{w}}^{o}\right|=-\frac{\left(v_{A}^{1}-\tilde{v}_{A}^{1}\right)+v_{B}^{1}}{\eta-\left[\eta_{A}^{1}\left(v_{A}^{1}-\tilde{v}_{A}^{1}\right)+\eta_{B}^{1} v_{B}^{1}\right]}>\hat{\tilde{w}}^{r}>0 .
$$

I.e., a regime switch of type $o$ implies a wage effect of a larger magnitude than does a shift of type $r$, due to the second-order effect which works in opposite directions for the two shifts. This is because in the above analysis elasticities of labor demand operate on a level of demand equal to $\tilde{V}_{w}^{1}+V_{w}^{2}+\Delta^{r} V^{1}$ for a shift of type $r$, and on a lower level $\tilde{V}_{w}^{1}+V_{w}^{2}-\Delta^{r} V^{1}$ for a shift of type $o$. Hence, the magnitude of the equilibrating wage adjustment is larger for an $o$-type shift than for an $r$-type shift.

To complete the analysis, we may now ask how $\hat{\tilde{w}}^{r}$ and $\left|\hat{\tilde{w}}^{o}\right|$ vary with $\tilde{w} / w^{f}$. In line with the above, we restrict ourselves to $\tilde{w} / w^{f}<1$. The direct labor demand effect of a regime shift, $\Delta^{r} V^{1}=\left|\Delta^{o} V^{1}\right|$, is falling in $\tilde{w} / w^{f}$. The larger the the demand shift, the larger - ceteris paribus - the magnitude of the ensuing wage effect. Hence, we expect two downward-sloping schedules $\left|\hat{\tilde{w}}^{o}\right|=\Omega^{o}\left(\tilde{w} / w^{f}\right)$ and $\hat{\tilde{w}}^{r}=\Omega^{o}\left(\tilde{w} / w^{f}\right)$. Although there are also indirect effects operating through potential changes in the elasticities appearing in the denominators of 23 , it appears reasonable to assume that the direct effect is dominating. ${ }^{19}$ Figure 3 depicts the two schedules, again restricted to the range $\tilde{w}<w^{f}$.

A general equilibrium requires that a wage rate from 14 satisfies

$$
\begin{aligned}
\left|\hat{\tilde{w}}^{o}\right| & =\Omega^{o}\left(\tilde{w} / w^{f}\right) \leq \Gamma^{o}\left(\tilde{w} / w^{f}\right) \\
\text { and } \quad \hat{\tilde{w}}^{r} & =\Omega^{r}\left(\tilde{w} / w^{f}\right) \geq \Gamma^{r}\left(\tilde{w} / w^{f}\right)
\end{aligned}
$$

\footnotetext{
${ }^{19}$ For constant labor demand elasticities, the denominator of 23 is increasing in absolute value in $\tilde{w} / w^{f}$, which would imply that $\left|\hat{\tilde{w}}^{o}\right|$ can be seen as a downward-sloping function $\Omega^{o}\left(\tilde{w} / w^{f}\right)$. However, even if labor demand elasticities are constant, $\eta$ varies with $\tilde{w} / w^{f}$ through an associated variation in $\nu$. Without digging deeper, we cannot rule out an upward-sloping schedule $\Omega^{o}\left(\tilde{w} / w^{f}\right)$. For 21 , the denominator is falling in $\tilde{w} / w^{f}$, hence even for constant elasticities the slope of $\Omega^{r}\left(\tilde{w} / w^{f}\right)$ is ambiguous.
} 
The first condition states that the wage rate must be such that a representative domestic firm has no incentive to shift towards an outsourcing strategy, while the second condition states that for the same wage rate a representative fragmented firm has no incentive for returning in order to become a purely domestic firm.

While the schedules $\Omega^{r}$ and $\Omega^{o}$ as such are defined for any domestic wage rate, it is important to see that, in line with 14, it is changes in $\nu$ that give rise to alternative values of $\tilde{w}$ along the horizontal axis. The model jointly determines the equilibrium wage rate and the fraction of fragmented firms $\nu$. But as we have emphasized above, given the underlying indivisibility of assets $\bar{k}_{B}^{1}$, we cannot treat $\nu$ as a continuous variable. Thus, if we take into account the discrete nature of $\nu$ in 14, then only a limited number of points along the horizontal axis in figure 3 are relevant. However, at each point there is a unique value of both $\Omega^{o}$ and $\Omega^{r}$, as well as $\Gamma^{o}$ and $\Gamma^{r}$. There is, of course a lower bound for the wage rate which is reached with $\nu=1$, which is equivalent to the single-firm case described above. Figure 3 clearly indicates the possibility of an equilibrium with $\tilde{w}<w^{f}$ also for the case where $n>1$. The subsequent section explores some features of this equilibrium.

\subsection{Existence, uniqueness and adjustment}

Although the above analysis does not include any explicit adjustment mechanism, figure 3 indicates adjustment taking place if 24 or 25 is violated. For any wage rate $\tilde{w}$ above $\tilde{w}_{1}$ domestic firms shift to outsourcing, while for $\tilde{w}<\tilde{w}_{0}$ fragmented firms shift to an integrated production in the domestic economy. Will there always exist an equilibrium with a unique value of $\nu$, and a unique value of $\tilde{w}$, given that $\nu$ cannot adjust continuously? From figure 3, it cannot be ruled out that there is no relevant equilibrium point according to 14 within the interval $\left[\tilde{w}_{0}, \tilde{w}_{1}\right]$. Indeed, if the schedules $\Omega^{o}$ and $\Omega^{r}$ are sufficiently far apart, this interval is empty. The difference between these two schedules is, however, only due to the second order effect (see above), and I henceforth rule out this case. But even in the case depicted, the interval may not contain any of the relevant points corresponding to 14. In such a case no equilibrium with a unique $\nu$ exists. Intuitively, as fragmented firms approach $\tilde{w}_{0}$ from the left, they would eventually come to a "return shift" which increases the domestic wage beyond $\tilde{w}_{1}$. Conversely, if domestic firms approach $\tilde{w}_{1}$ from the right, a further shift towards outsourcing would depress $\tilde{w}$ below $\tilde{w}_{0}$. One could explore this case further into the possibility of equilibria in mixed strategies. However, as with the 
oscillating equilibrium in the non-cooperative case mentioned above, this is a questionable interpretation, as it ignores the cost of shifting from one regime to the other. In terms of figure 3 , such costs would increase the vertical distance between the two schedules $\Omega^{o}$ and $\Omega^{r}$, thus also increasing the interval $\left[\tilde{w}_{0}, \tilde{w}_{1}\right]$ and making this case seem somewhat unlikely.

However, a large interval $\left[\tilde{w}_{0}, \tilde{w}_{1}\right]$ begs the question of multiplicity in that there may be more than one labor-market-clearing value $\tilde{w}$ within this interval. This issue can be resolved by stipulating a specific adjustment process. If one assumes that firms are purely domestic to start with, then a process of increasing fragmentation approaches the equilibrium domestic wage rate from above (or the right in figure 3). The opposite, perhaps less convincing, assumption would be that fragmented firms increasingly return fragment $B$ to the home economy, in which case the equilibrium wage rate is reached from below.

Any outsourcing shift, by depressing the domestic wage rate, increases both $v_{A}^{1}-\tilde{v}_{A}^{1}$ and $v_{B}^{1}$. In turn, this increases the direct labor demand effect of a further shift, and thus $\left|\hat{\tilde{w}}^{o}\right|$ according to the schedule $\Omega^{o}$. But so does the critical level $\left|\omega^{o}\right|$ according to $\Gamma^{o}$. The slopes in figure 3 imply that this latter effect always dominates, such that the adjustment process leads to a unique interior equilibrium. Suppose, however, that the effect of an outsourcing shift on $\left|\hat{\tilde{w}}^{o}\right|$ dominates that on $\left|\omega^{o}\right|$, and analogously for the "return-shift". Then, the slopes of the the $\Omega$-schedules are steeper than the $\Gamma$-schedules, as drawn in figure 4 . To the left of $\tilde{w}_{0}$, outsourcing shifts would further enhance the case for outsourcing, and conversely for "return-shifts" to the right of $\tilde{w}_{1}$. This suggests the possibility of unstable interior equilibria. Notice, however, that for $\tilde{w} / w^{f}=1$ the $\Gamma$-lines always intersect with the horizontal axis, while the $\Omega$-lines are clearly positive. Hence, barring the aforementioned problems related to discontinuity, there is a stable interior equilibrium close to $\tilde{w} / w^{f}=1$. This, in turn, implies that in the case depicted in figure 4 , there must actually be multiple intersections between the $\Omega$ - and the $\Gamma$-lines. However, the interesting point emerging from this analysis is that even in a multiple-firm case without collusion, there may be an equilibrium with $\nu=1$.

A final point worth mentioning is that in any interior equilibrium fragmented firms have lower profits (or capital rental) than purely domestic firms. By assumption, all firms share the same technology, but domestic firms enjoy a lower (domestic) wage on fragment 
$B$ than fragmented firms who use foreign labor. ${ }^{20}$ This raises the question of why any firm should choose an outsourcing strategy in stage one, knowing that the equilibrium features a coexistence of both strategies, with higher profits for the strategy of integrated production. One can rely on at least two different interpretations of the equilibrium when trying to answer this question. The first is a probabilistic interpretation, as often suggested for equilibria where symmetric agents find different "treatments". The model determines the equilibrium share of fragmented firms, but leaves open whether a specific firm will end up as a domestic or a fragmented firm, which can then be seen as the outcome of a draw. Of course, indeterminacy on the individual level will disappear if a specific form of asymmetry between firms is introduced. For instance, there may be an asymmetry among firms, unrelated to their fundamental technology, which determines a well-specified sequencing of firm decisions on choosing their production regime. In view of the above discussion on uniqueness, this could be combined with an assumption about a specific starting point, in which case the position of individual firms is determined endogenously. I do not, however, explore this any further in this paper.

\section{Remarks on the potential welfare loss}

When discussing the single-firm and the cooperative case in figure 2, we have noted the possibility of a welfare loss from fragmentation. This possibility is upheld in the non-cooperative multiple firm case, if the equilibrium wage rate $\tilde{w}$ is sufficiently below $w^{f}$. From the preceding analysis, we can identify some of the forces determining the equilibrium magnitude of $w^{f}-\tilde{w}$. Other things equal, the vertical position of the $\Omega$-lines are important. This is most easily pinned down by looking at $\Omega^{\circ}(1)=-v_{B}^{1} /\left(\eta-\eta_{B}^{1} v_{B}^{1}\right)$ and $\Omega^{r}(1)=-v_{B}^{1} /\left(\eta+\eta_{B}^{1} v_{B}^{1}\right)$, where $v_{B}^{1}=V_{B}^{1}\left(w^{f}, \bar{K}_{A}^{1}, \bar{K}_{B}^{1}\right) / n \bar{L}$. In other words, the share of an individual firm's fragment $B$ labor demand in overall labor endowment, evaluated at $w=w^{f}$, relative to the aggregate domestic labor demand elasticity, plays an important role. The welfare loss is more likely if this share is large.

For a given vertical position of the $\Omega$-lines, the relative slopes of the $\Omega$ - and $\Gamma$-lines are important. In particular, the flatter the $\Gamma$-lines, the more likely a welfare loss. In

\footnotetext{
${ }^{20}$ Domestic labor, of course, receives a uniform wage rate in all domestic employment.
} 
particular, if $\varphi_{B}^{1} / \varphi_{A}^{1}$ is small, then the slope of $\Gamma^{o}$ in figure 3 is relatively small and other things equal - the equilibrium value of $w^{f}-\tilde{w}$ is large. Indeed, as noted above, there may be intersection points where the $\Omega^{o}$-line is steeper than the $\Gamma^{o}$-line, in which case the equilibrium may even involve $\nu=1$, as in the single-firm case discussed above.

There is a further subtle issue of interpretation relating to the vertical position of the $\Omega$-lines which, as we have just seen, is important for whether a welfare loss from fragmentation obtains. When identifying the possibility of such a loss by means of figure 2 , the reference equilibrium was one where the domestic labor market is characterized by perfect competition. One may now argue that in a case where $\Omega^{o}(1)$ and $\Omega^{r}(1)$ are large is also a case where a single domestic firm in industry 1 is large enough to have market power on the domestic labor market. If so, it questions the validity of a competitive reference equilibrium against which to evaluate the welfare effects of fragmentation. It should be noticed, however, that the relevant magnitude is the size of a domestic industry 1 firm relative to the overall labor demand elasticity $\eta$. More importantly, one should bear in mind the two-stage nature of the decision making that underlies this analysis, as well as the discontinuity involved in stage one. Specifically, stage one by definition always involves discrete variations in labor demand, whereby firms look at alternative cases where their fragment $B$ capital stocks $\bar{k}_{B}^{1}$ are invested domestically, or abroad. By way of contrast, in stage two, once the investment decision has been made, labor demand is always a matter of a truly marginal decision, where firms are less likely to perceive themselves as having influence on the domestic wage rate.

This is not to deny the possibility that the kind of indivisibility underlying the analysis may lead to market power of industry 1 firms on the domestic labor market. If that is the case, then the reference equilibrium for evaluating international fragmentation involves a distortion in the domestic labor market to start with, implying that too much labor is employed in industry 2, and too little in industry 1 where the wage rate is below the marginal productivity of labor. In a globalization scenario where lower costs of international fragmentation cause international outsourcing there will, then, be first-order welfare effects which we did not cover in the above analysis. A full-fledged analysis of this case is beyond the scope of the present paper, but it is important to bear in mind this complication when interpreting the results.

How does the welfare loss from fragmentation in this model relate to other cases where international division of labor is not beneficial to all countries involved? First, there is 
no terms of trade effect involved, and there is no offsetting gain in the foreign economy. Indeed, under the assumptions made, the foreign economy neither gains nor loses from fragmentation. Secondly, there is no distortion at the margin to start with, which would explain the welfare loss as a second-best phenomenon. Thirdly, the loss is also not of the Graham-type where in the presence of scale economies a country ends up "at the wrong" end of international specialization. The crucial point is that participation in the international division of labor may only take in discrete steps, rather than marginally. If this option arises for a relatively small number of firms, then it affords them "quasi-market-power" on the domestic labor market, with the potential of a welfare loss. Without jumping too far, the analysis suggests that trade theory, with its tendency to portray internationalization under conditions where agents move in infinitesimally small steps, may ignore important consequences of the real world where, in some areas at least, globalization involves certain discontinuity of adjustment.

One may finally wonder about the empirical relevance of a case where international outsourcing to a low-wage foreign country leads to a domestic wage rate which is below the foreign wage rate. But this is easily resolved by remembering that wage rates in this context are wage rates for comparable efficiency units, and even if $\tilde{w}<w^{f}$ the wage rate for a natural unit of labor may well continue to be higher domestically than abroad.

\section{Conclusions}

In concluding, I should like to offer a few remarks on how this analysis should be interpreted, given the assumptions made. The underlying assumption is that labor markets are sometimes pretty regional in nature, with a high degree of labor mobility between a relatively small number of industries within a small region, but with very low mobility across such regions, despite potentially sizable wage differences. This seems a reasonable assumption particularly in the European context, where outsourcing then seems an interesting option for firms to arbitrage on wage differences across small labor markets. The purpose of this paper is to offer a framework of analysis which juxtaposes the efficiency and distributional effects arising from such arbitrage. Although the paper has stopped way before suggesting specific policy measures, a number of important insights have emerged.

The analysis confirms the a-priori intuition that domestic labor initially employed in 
those value-added fragments lost to foreign regions will always lose, while other factors gain. As to the efficiency effect of fragmentation, the crucial question emphasized by the above analysis is whether or not the resources set free through outsourcing will find alternative employment where they generate value-added which is equal to what they have earned before. Thus, one must look at what outsourcing implies for the activities that remain in the domestic region. It is often argued that these activities will in some sense benefit from the cost-advantage that comes with outsourcing. This paper has focused on exactly this linkage, assuming that mobile domestic labor is employed alongside sectorspecific factors, and exploring the effect of outsourcing on labor demand for the remaining domestic part of production.

The analysis reveals that, potentially unwelcome distributional implications notwithstanding, a region that loses some fragment of its domestic value-added through outsourcing, will reap a welfare gain, provided such outsourcing does not involve any non-convexity in technology. The welfare gain identified has a close resemblance to the well-known "immigration surplus". However, the relationship between the "outsourcing surplus" and redistribution is the opposite of the usual story: The larger the gain, the lower the pain of redistribution.

If international fragmentation is subject to the presence of fixed assets that can either be deployed (or serve production) at home or abroad, then outsourcing is a discrete event, with important consequences for welfare. The cost-savings linkage to domestic activities notwithstanding, labor which is set free through outsourcing may not generate sufficient value-added in its alternative domestic use for fragmentation to be welfare enhancing. This holds true even under otherwise optimal factor market institutions ruling out distortions or unemployment. The crucial point is that to reap the gains from lower foreign wages, firms have to move in discrete steps, if outsourcing involves alternative deployment of indivisible assets, like capital.

The paper has modeled such discrete shifts between domestic and fragmented modes of production as a two-stage game, where stage 1 involves deploying indivisible assets either at home or abroad, and stage 2 involves profit maximizing labor demand at home and abroad. The option of outsourcing affords domestic firms "quasi-market-power" on the domestic labor market, even if they behave competitively in stage 2 . The resulting fragmentation equilibrium may be such that international fragmentation which is caused by a lower costs of outsourcing may involve a welfare loss. The analysis has identified 
specific conditions that are important for whether or not such a loss arises.

Whether or not these conditions are fulfilled in specific instances of fragmentation, is an empirical matter. The above analysis should, thus, be a valuable guide to future empirical research on outsourcing. Moreover, future theoretical work should foucus on cases where the reference equilibrium features labor market distortions that may arise from the kind of indivisibility emphasized in this paper. 
Figure 1: Welfare and distributional effects of international fragmentation Case I - no indivisibility

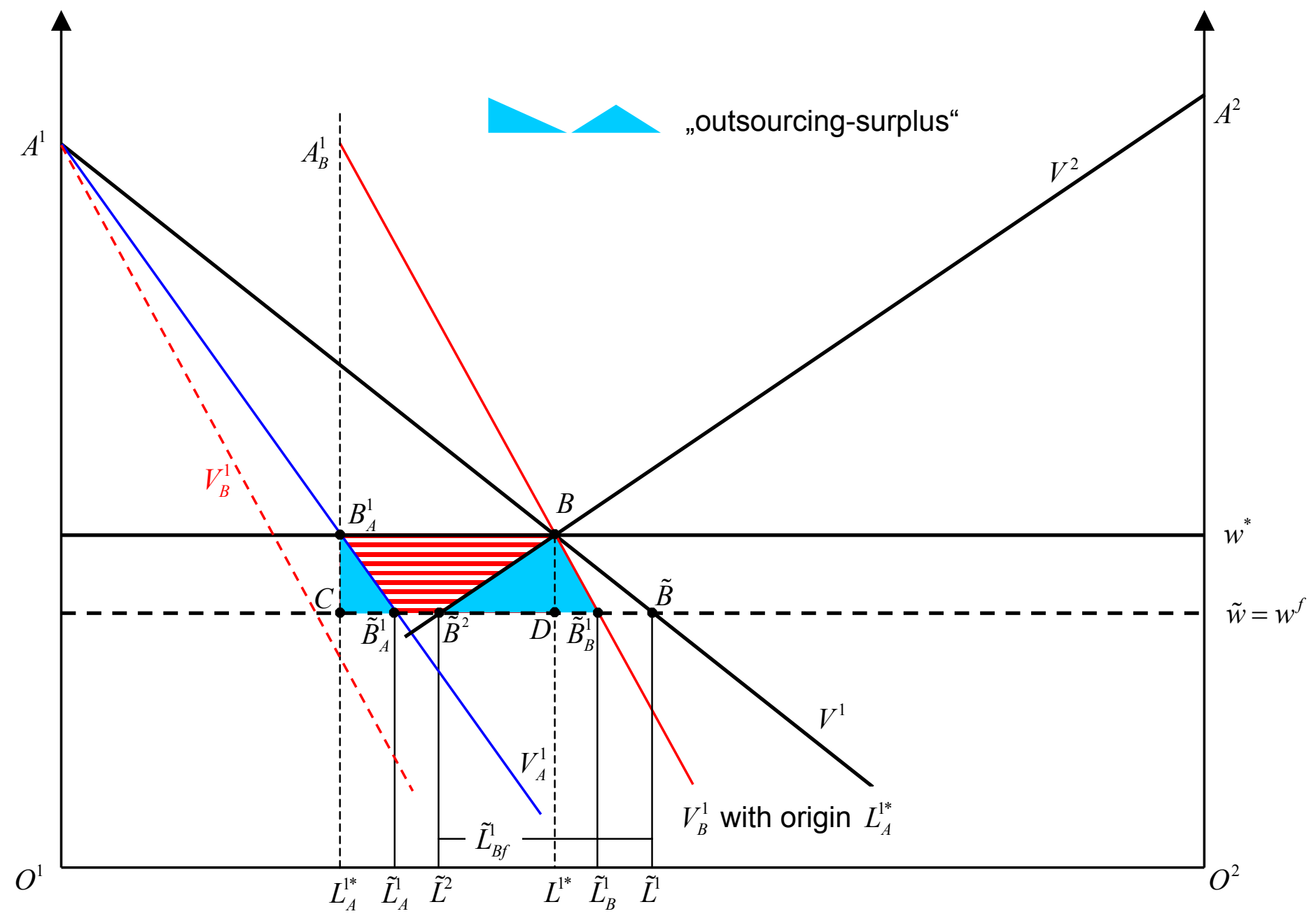


Figure 2: Welfare and distributional effects of international fragmentation Case II - indivisible capital stock

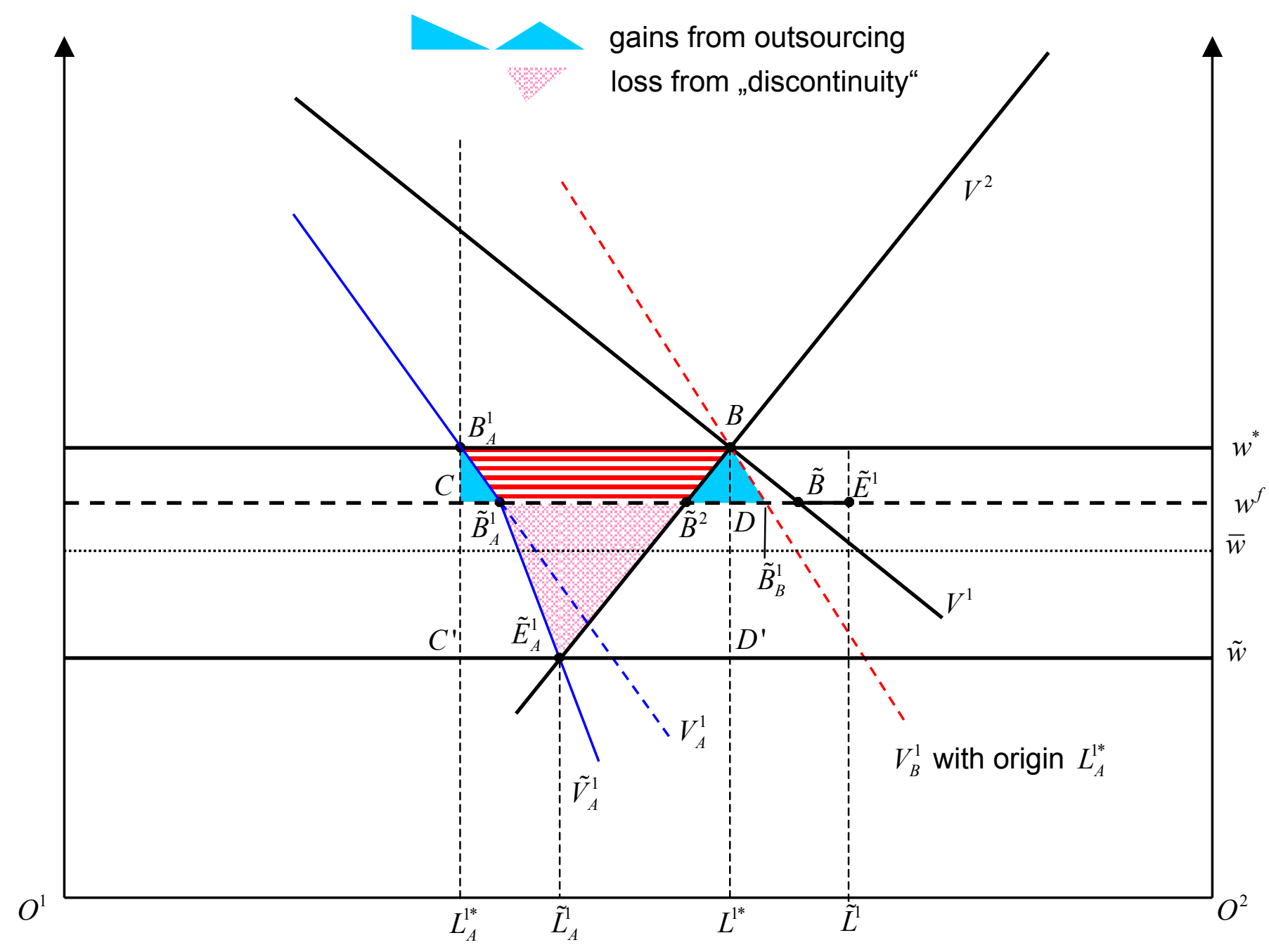


Figure 3: Indivisibility and non-cooperative "fragmentation equilibrium" stable interior equilibrium

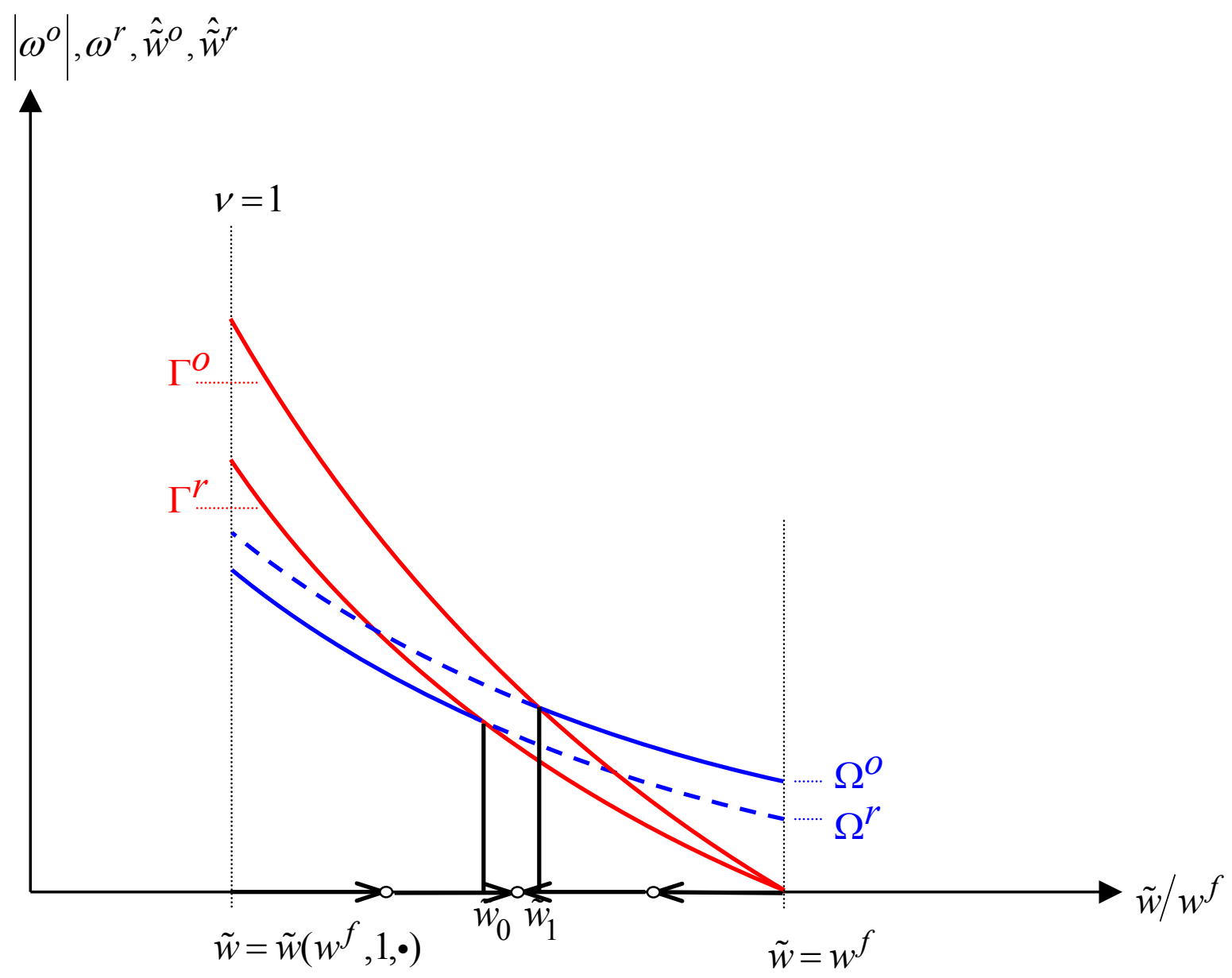


Figure 4: Indivisibility and non-cooperative "fragmentation equilibrium" stable interior equilibrium

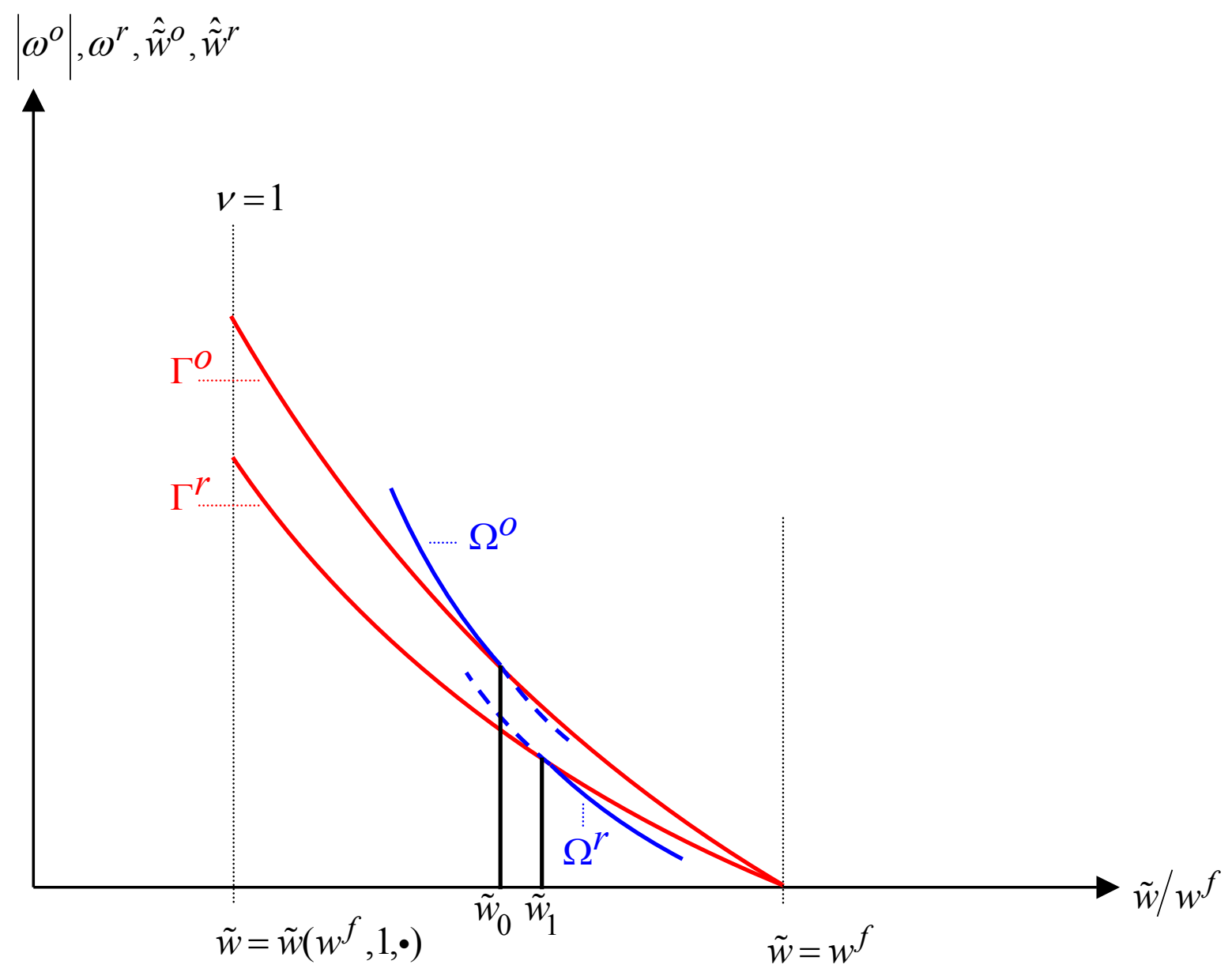




\section{References}

Arndt, S.W. (1997), 'Globalization and the Open Economy', North American Journal of Economics and Finance 8, 71-79.

Arndt, S.W. (1999), 'Globalization and Economic Development', The Journal of International Trade and Economic Development 8, 309-318.

Arndt S.W. and H. Kierzkowski, eds. (2001), Fragmentation: New Production Patterns in the World Economy, Oxford University Press, Oxford.

Borjas, G. (1999), 'The Economic Analysis of Immigration', in: Ashenfelter, O. and D. Card (eds.), Handbook of Labor Economics, Vol. 3A, Elsevier (North-Holland), Amsterdam 1999, 1697-1760.

Deardorff, A.V. (2001a), 'Fragmentation Across Cones', in: Arndt, S.W. and H. Kierzkowski (eds.), Fragmentation: New Production Patterns in the World Economy, Oxford University Press, Oxford.

Deardorff, A.V. (2001b), 'Fragmentation in Simple Trade Models'. North American Journal of Economics and Finance 12, 121-137.', Journal of Economic Perspectives 12, 31-50.

Feenstra, R.C. and G.H. Hanson (1996), 'Foreign Investment, Outsourcing and Relative Wages', in: R.C. Feenstra et al. (eds.), Political Economy of Trade Policy: Essays in Honor of Jagdish Bhagwati, MIT Press, Cambridge, Mass., 89-127.

Feenstra, R.C. and G.H. Hanson (1997), 'Foreign Direct Investment and Relative Wages: Evidence from Mexico's Maquiladoras', Journal of International Economics 42, 371393.

Feenstra, R.C. and G.H. Hanson (1999), 'The Impact of Outsourcing and High-Technology Capital on Wages: Estimates for the United States, 1979-1990', Quarterly Journal of Economics 114, 907-940.

Harris, R.G. (1995), 'Trade and Communication Costs', Canadian Journal of Economics $28,46-75$.

Hummels, D., D. Rapoport, J. Ishii and .K. Yi (1998), 'Vertical Specialization and the Changing Nature of World Trade', Federal Reserve Band of New York Economic Policy Review June 1988, 79-99.

Hummels, D., J. Ishii and K. Yi (2001), 'The Nature and Growth of Vertical Specialization in World Trade', Journal of International Economics 54, 75-96. 
Irwin, D.A. (1996), 'The United States in a New Global Economy? A Century's Perspective', American Economic Review, Papers and Proceedings 86, 41-46.

Jones, R.W. (1971), 'A Three-Factor Model in Theory, Trade, and History', in: J. Bhagwati et al. (eds.), Trade, Balance of Payments and Growth: Essays in Honor of Charles Kindleberger, North-Holland, Amsterdam, 3-21.

Jones, R.W. and H. Kierzkowski (1990), 'The Role of Services in Production and International Trade: A Theoretical Framework', in: R.W. Jones and A.O. Krueger (eds.), The Political Economy of International Trade, Basil Blackwell, Oxford, 31-48.

Jones, R.W. and H. Kierzkowski (2001a), 'A Framework for Fragmentation', in: Arndt, S.W. and H. Kierzkowski (eds.), Fragmentation: New Production Patterns in the World Economy, Oxford University Press, Oxford.

Jones, R.W. and H. Kierzkowski (2001b), 'Globalization and the Consequences of International Fragmentation', in: Calvo, G.A. et al. (eds.), Money, Capital Mobility, and Trade, Essays in Honor of Robert A. Mundell, MIT Press, Cambridge, Mass.

Kohler, W. (2001), 'A Specific Factors View on Outsourcing', North American Journal of Economics and Finance 12, 31-53.

Kohler, W. (2003), 'The Distributional Effects of International Fragmentation', German Economic Review 4, 89-120.

Krugman, P. (1995), 'Growing World Trade: Causes and Consequences', Brookings Papers on Economic Activity 1:1995, 327-377.

Markusen, J.R. (2002), Multinational Firms and the Theory of International Trade, MIT Press, Cambridge, Mass.

Rodrik, D. (1997), Has Globalization Gone Too Far?, Institute for International Economics, Washington D.C.

Rodrik, D. (1998), 'Symposium on Globalization in Perspective: An Introduction', Journal of Economic Perspectives 12, 3-8.

Venables, A.KJ. (1999), 'Fragmentation and Multinational Production', European Economic Review 43, 935-945. 